\title{
Assessment of Indicators of the Circular Economy on the Example of the Countries of the European Union and the Possibility of Application in the Conditions of Kazakhstan
}

\author{
Arsen M. Tleppayev ${ }^{* *}$, Saule Zh. Zeinolla ${ }^{2}$ \\ ${ }^{1}$ Kazakh-German University, 111 Pushkin Str., 050010, Almaty, Kazakhstan, \\ ${ }^{2}$ Academy of Public Administration under the President of the Republic of Kazakhstan \\ 134 Dostyk Str., 050051, Almaty, Kazakhstan
}

\begin{abstract}
The purpose of this study is to study the approaches to measuring the indicators of the circular economy used in the countries of the European Union and in the OECD countries to form an understanding of the applicability of the presented methods. The study used the methods of econometric modeling, statistical and comparative analyzes. A model was built using data for the European Union countries, the following variables (factors) were used to build this model: the share of material extracted and returned to the economy, the intensity of $\mathrm{CO} 2$ emissions, the level of energy intensity of primary energy, GDP per capita, research and development costs, the share urban population in total. Based on the simulation results, it was concluded that GDP growth and growth in energy intensity, together with an increase in the level of technology in the economy, leads to an increase in the processing of materials and their reuse in economic circulation. The results of modelling confirm the conclusions of the previous authors, the analysis of the strategies of the EU and OECD countries. It is necessary to invest more financial resources in R\&D, development of new technologies and innovations for achieve better results. Greater involvement of consumers and businesses in activities conducive to the circular economy is also critical. Achieving these two goals will contribute to sustainable economic development. Based on the analysis of the model and strategies of the OECD and EU countries on the circular economy, we concluded that international innovations in the circular economy are applicable to Kazakhstan's economy.
\end{abstract}

Keywords: circular economy, indicator, model, green economy, forecasting

For citation: Tleppayev, A.M. \& Zeinolla, S.Zh. (2021). Assessment of Indicators of the Circular Economy on the Example of the Countries of the European Union and the Possibility of Application in the Conditions of Kazakhstan. Economics: the Strategy and Practice, 16(3), 128-141, https://doi.org/10.51176/1997-9967-2021-3-128-141

* Corresponding author: Arsen M. Tleppayev - PhD (Economics), Associate Professor, Faculty of Economics and Business, Kazakh-German University, 111 Pushkin Str., Almaty, 050010, Kazakhstan, e-mail: arsentlp@gmail.com

Conflict of interests: the authors declare that there is no conflict of interest.

Financial support: Research funding source: this research was funded by the Science Committee of the Ministry of Education and Science of the Republic of Kazakhstan under the project AP09258860.

The article received: 14.06 .2021

The article approved for publication: 10.07 .2021

Date of publication: 30.09 .2021 


\title{
Еуропалық Одақ елдерінің мысалында циркулярлы экономика көрсеткіштерін бағалау және оны Қазақстан жағдайында қолдану мүмкіндігі
}

\author{
Тлеппаев А. ${ }^{*}$, Зейнолла С. ${ }^{2}$ \\ ${ }^{1}$ Қазақустан-неміс университеті, Пушкина к., 111, 050010, Алматы, Қазақустан \\ ${ }^{2}$ Қазақстан Республикасы Президентінің жанындавы Мемлекеттік басқару академиясы \\ Достык д., 134, 050051, Алматы, Қазақсстан
}

\begin{abstract}
Түйін
Зерттеудің мақсаты - Еуропалық Одақ елдерінде және ЭЫдҰ елдерінде қолданылатын айналым экономикасының көрсеткіштерін өлшеу тәсілдерін зерттеу, ұсынылған әдістердің. Сонымен қатар, қазіргі заманғы жағдайлар белгісіздік деңгейінің өсуімен сипатталады, сонымен қатар өмірдің барлық салаларына әсер ететін және қатаң әрекетті қажет ететін жаһандық сынақтар мен қатерлердің фонында жүзеге асады. Бұл жағдайына сәйкес деректерді алуға және экономиканың циркулярлық тәсілдерін енгізу үшін пайдалы және тәжірибеге бағытталған ұсыныстарды қалыптастыруға мүмкіндік беретін әр түрлі зерттеу әдістерін таңдау қажеттілігін анықтайды. Зерттеу барысында эконометрикалық модельдеу, статистикалық және салыстырмалы талдау әдістері қолданылды. Еуропалық Одақ елдері үшін деректер негізінде модель құрылды, осы модельді құру үшін келесі айнымалылар (факторлар) пайдаланылды: өндірілген және экономикаға қайтарылған материалдардың үлесі, СО2 шығарындыларының қарқындылығы, бастапқы энергияның энергия сыйымдылығы деңгейі, Жан басына шаққандағы ЖІӨ, ғылыми-зерттеу және тәжірибелік- конструкторлық жұмыстарға шығындар, жалпы қала халқының үлесі. Моделдеу нәтижелер негізінде ЖІӨ өсуі және энергия сыйымдылығының өсуі экономикадағы технология деңгейінің жоғарылауымен бірге материалдарды өңдеудің ұлғаюына және оларды экономикалық айналымда қайта пайдалануға әкеледі деген қорытынды жасалды. Моделдеу нәтижелер алдыңғы авторлардың тұжырымдарын, ЕО және ЭЫДҰ елдерінің стратегияларының талдауларын растайды. Жақсы нәтижеге жету үшін ғылыми-зерттеу жұмыстарына, жаңа технологиялар мен инновацияларға көп қаржы ресурстарын инвестициялау қажет. Тұтынушылар мен бизнесті дөңгелек экономикаға ықпал ететін іс-шараларға кеңінен тарту да өте маңызды. Осы екі мақсатқа қол жеткізу тұрақты экономикалық дамуға ықпал етеді. ЭЫДҰ және ЕО елдерінің шеңбер экономикасы бойынша моделі мен стратегияларын талдау негізінде шеңбер экономикасындағы халықаралық инновациялар Қазақстанға қатысты деген қорытындыға келді.еңбер экономикасындағы халықаралық инновациялар Қазақстанға қатысты деген қорытындыға келді.
\end{abstract}

Түйін сөздер: айналмалы экономика, индикатор, модель, жасыл экономика, болжам.

Дәйексөз алу үшін: Тлеппаев А., Зейнолла С. (2021). Еуропалық Одақ елдерінің мысалында циркулярлы экономика көрсеткіштерін бағалау және оны Қазақстан жағдайында қолдану мүмкіндігі. Экономика: стратегия және практика, 16(3), 128-141, https://doi.org/10.51176/1997-9967-2021-3-128-141

* Хат-хабаршы авторы: Арсен Тлеппаев - PhD, доцент, экономика және кәсіпкерлік факультеті, ҚазақстанНеміс Университеті, Пушкина 111,050010, Алматы, Казахстан, arsentlp@gmail.come-mail: arsentlp@gmail.com

Мүдделер қақтығысы: авторлар мүдделер қақтығысының жоқтығын мәлімдейді.

Қаржыландыру. Зерттеуді қаржыландыру көзі: бұл зерттеуді ҚР БҒМ Ғылым комитеті АР09258860 жобасы аясында қаржыландырды

Мақала редакцияға түсті: 14.06 .2021

Жариялау туралы шешім қабылданды: 10.07 .2021

Жарияланды: 30.09 .2021 


\title{
Оценка показателей циркулярной экономики на примере стран Европейского союза и возможности ее применения в условиях Казахстана
}

\author{
Тлеппаев A. ${ }^{*}$, Зейнолла C. ${ }^{2}$ \\ ${ }^{1}$ Казахстанско-немецкий университет, ул. Пушкина 111, 050010, Алматы, Казахстан \\ ${ }^{2}$ Академия государственного управления при Президенте Республики Казахстан, \\ Достык 134, 050051, Алматы, Казахстан
}

\begin{abstract}
Аннотация
Цель данного исследования заключается в изучении подходов измерения показателей циркулярной экономики, используемых в странах Европейского союза и в странах ОЭСР для формирования понимания применимости представленных методик. В рамках исследования были применены методы эконометрического моделирования, статистического и сравнительного анализов. Построена модель с использованием данных по странам Европейского союза, для построения указанной модели использовались следующие переменные (факторы): доля материала, извлеченного и возвращенного в экономику, интенсивность выбросов СО2, уровень энергоемкости первичной энергии, ВВП на душу населения, затраты на исследования и разработки, доля городского населения в общей численности. По результатам моделирования был сделан вывод, что рост ВВП и рост энергоемкости вместе с повышением уровня технологий в экономике ведет к росту переработки материалов и их повторному использованию в экономическом обороте. Результаты моделирования подтверждают выводы предыдущих авторов, анализ стратегии стран ЕС и ОЭСР. Для достижения лучших результатов необходимо инвестировать больше финансовых ресурсов в НИОКР, разработку новых технологий и инновации. Очень важно также более активное вовлечение потребителей и бизнеса в деятельность, способствующую циркулярной экономике. Достижение этих двух целей будет способствовать обеспечению устойчивого экономического развития. На основе анализа модели и стратегий стран ОЭСР, и ЕС по циркулярной экономике сделан вывод, что международные инновации циркулярной экономики применимы к экономике Казахстану.
\end{abstract}

Ключевые слова: циркулярная экономика, индикатор, модель, зеленая экономика, прогнозирование

Для цитирования: Тлеппаев А., Зейнолла С. (2021). Оценка показателей циркулярной экономики на примере стран Европейского союза и возможности её применения в условиях Казахстана. Экономика: стратегия и практика, 16(3), 128-141, https://doi.org/10.51176/1997-9967-2021-3-128-141

* Корреспондирующий автор: Арсен М. Тлеппаев - PhD, доцент, Факультет экономики и бизнеса, Казахстанско-Немецкий университет, ул. Пушкина, 111, Алматы, 050010, Казахстан, e-mail: arsentlp@gmail. $\underline{\text { com }}$

Конфликт интересов: авторы заявляют об отсутствии конфликта интересов.

Финансирование. Исследование было профинансировано Комитетом науки МОН РК в рамках проекта AP09258860

Статья поступила в редакцию: 14.06 .2021

Принято решение о публикации: 10.07 .2021

Опубликовано: 30.09 .2021 


\section{Введение}

Тенденции развития мирового сообщества в последние десятилетия характеризуются тем обстоятельством, что люди производят и используют все больше и больше ресурсов, материалов и энергии, и вопросы сохранения окружающей среды и переработки становятся все более важными факторами, влияющими на общественное развитие. В рамках данного исследования важно изучить экономические факторы устойчивого развития циркулярной экономики, основываясь на результатах и выводах научной литературы в этой области и выработать рекомендации для продвижения в Республике Казахстан.

Глобальные вызовы, которые стоят перед мировой экономикой с каждым годом становятся все более комплексными и масштабными. Как пример пандемия COVID-19, влияние которой потрясает и отражается на развитие каждой экономики и каждого, отдельно взятого человека. Так, эксперты KPMG в своем исследовании указывают, что по предварительным оценкам ряда экономистов, текущий мировой кризис может стать самым глубоким со времен Второй Мировой Войны. Резкое сжатие рынков сбыта и разрыв цепочек поставок, отмена авиаперелетов и ограничение свободного перемещения граждан, массовый переход на режим самоизоляции спровоцировал значительное сжатие бизнеса в разных отраслях [1].

Описанная ситуация, несомненно, негативно отражается на устойчивости мировой экономики, особенно по экологическим, социальным и экономическим направлениям. Именно по этой причине, концепция циркулярной экономики приобрела значительный импульс во всем мире, поскольку традиционно известная линейная экономика, основанная на модели «взять изготовить - утилизировать», по-прежнему не справляется с задачами устойчивого развития мира, который одновременно требует устойчивого экономического роста, защиты окружающей среды и общественного благополучия [2]. В этой ситуации важно найти подходы, позволяющие выстраивать эффективные экономические системы, отличающиеся высокой устойчивостью и основанные на принципах ресурсосбережения и разумного отношения к окружающей среде. Ocобое внимание в данном направлении привлекают вопросы того, каким образом можно наиболее эффективно продвинуть принципы циркулярной экономики в условиях казахстанской экономики, на какие аспекты стоит обратить особое внимание и какой лучший опыт из мировой практики наиболее применим. При этом основной упор при обзоре методов, подходов и измерений будет делаться на опыт стран ЕС.

\section{Литературный обзор}

Прежде всего стоит дать определение самому понятию циркулярная (замкнутая) экономика. Как отмечают Grdic at al (2020), само понятие циркулярной экономики начали активно обсуждать и исследовать с конца 60-х годов. До настоящего времени сама концепция все больше обогащалась новыми идеями и исследованиями [3]. В таблице 1 приводится обзор основных определений понятия циркулярная экономика. Конечно за указанный период было проведено множество исследований, но как кажется авторам, важно рассмотреть в ретроспективе, как дополнялась и менялась идея циркулярной экономике в научной среде, на примере некоторых идей и исследований.

Как было отмечено в таблице PrietoSandoval et al. (2018) дает следующее определение: «циркулярная экономика - это экономическая система, которая представляет собой изменение парадигмы в том, как человеческое общество взаимосвязано с природой и направлено на предотвращать истощение ресурсов, снижения энергетической и ресурсной зависимости, а также способствует устойчивому развитию, за счет внедрения на микро (предприятиях и потребителях), мезо (экономические агенты, интегрированные в симбиоз) и макро уровнях (город, регионы и правительства). Для достижения этой цикличной модели требуются системные и восстанавливающие экологические инновации в том, как общество принимает законы, производит и потребляет» [6]. Данное определение представляется наиболее полным и отражающим важные аспекты и элементы, характеризующие действие циркулярной экономики, что стало результатом продолжительного процесса исследований в данном направлении.

Так, в современном мировом пространстве сложилась линейная модель использования природных ресурсов «взять использовать - выбросить», основанная на предположении о том, что ресурсы имеются в изобилии, доступны, легки в использовании и дешевые. Решение вопросов эффективного использования природных ресурсов, позволяющих извлечь при их использовании экономическую и экологическую выгоды, является важной составляющей формируемого в настоящее время видения перспектив 
устойчивого развития мировой экономики. Для реализации задач в области ресурсосбережения в целях эффективного использования ресурсов большое значение имеет переход к циркулярной экономике [7].
Этот переход имеет большую значимость и для экономики Казахстана и должен быть основан на изучении как лучшего мирового опыта, так и страновых особенностей развития.

Таблица 1 - Обзор развития концепции циркулярной экономики

Table 1 - Overview of the development of the circular economy concept

\begin{tabular}{|c|c|c|}
\hline Автор (ы) & Основная идея & Ключевые моменты \\
\hline Bowding, 1966 & $\begin{array}{l}\text { Пришел к выводу, что экономика и окружающая среда } \\
\text { должны взаимодействовать гармонично, в равновесии }\end{array}$ & $\begin{array}{l}\text { Гармоничное } \\
\text { взаимодействие }\end{array}$ \\
\hline Pearce, Turner, 1970 & $\begin{array}{l}\text { Рассмотрели влияние природных ресурсов на экономические } \\
\text { системы. То, как они влияют и определяют ее эффективность } \\
\text { и развитие }\end{array}$ & $\begin{array}{l}\text { Влияние природных } \\
\text { ресурсов на экономику }\end{array}$ \\
\hline $\begin{array}{l}\text { David Pearce and R. } \\
\text { Kerry Turner } 1989\end{array}$ & $\begin{array}{l}\text { Показали, что традиционная экономика не принимает во } \\
\text { внимание переработку отходов. Это привело к тому, что } \\
\text { окружающая среда стала просто хранилищем отходов. В } \\
\text { отличие от традиционной и линейной экономики, девизом } \\
\text { которой было «извлекать, производить и отбрасывать», } \\
\text { концепция экономики замкнутого цикла возникла под } \\
\text { влиянием естественных циклических соображений. }\end{array}$ & $\begin{array}{l}\text { Окружающая среда } \\
\text { - это не только } \\
\text { хранилище отходов }\end{array}$ \\
\hline $\begin{array}{l}\text { McDonough and } \\
\text { Braungart } 2002\end{array}$ & $\begin{array}{l}\text { Концепция безотходного производства Cradle-to-Cradle, } \\
\text { независимая система сертификации, которая оценивает } \\
\text { безопасность продукции, базируясь на материалах и } \\
\text { производственных технологиях, использованных в её } \\
\text { создании }\end{array}$ & $\begin{array}{l}\text { Сертификация для } \\
\text { продвижения безот- } \\
\text { ходного производства }\end{array}$ \\
\hline Preston, 2012 & $\begin{array}{l}\text { Концепция основана на сотрудничестве между различными } \\
\text { участниками по всей цепочке создания стоимости. Подход } \\
\text { экономики замкнутого цикла требует системных изменений }\end{array}$ & $\begin{array}{l}\text { Системность измене- } \\
\text { ний в основе реали- } \\
\text { зации }\end{array}$ \\
\hline $\begin{array}{l}\text { European Commission } \\
2014\end{array}$ & $\begin{array}{l}\text { Концепция циркулярной экономики преобразовалась } \\
\text { в новую промышленную модель, которая могла бы } \\
\text { поддержать переход к другой экономической модели. } \\
\text { Циркулярная экономика основана на принципе замкнутой } \\
\text { системы, где окружающая среда и экономика связаны } \\
\text { отношениями }\end{array}$ & $\begin{array}{l}\text { Новая промышленная } \\
\text { модель }\end{array}$ \\
\hline Persson, 2015 & $\begin{array}{l}\text { Рассматривали циркулярную экономику как способ } \\
\text { преодоления ограничений ресурсов за счет непрерывного } \\
\text { обращения материалов, которые могут влиять на эконо- } \\
\text { мический рост независимо от добычи конечных ресурсов }\end{array}$ & $\begin{array}{l}\text { Экономический рост } \\
\text { не зависит от добычи } \\
\text { ресурсов }\end{array}$ \\
\hline $\begin{array}{l}\text { Prieto-Sandoval et al. , } \\
2018\end{array}$ & $\begin{array}{l}\text { На основании систематического исследования и обзора } \\
\text { имеющейся литературы сформировал определение цирку- } \\
\text { лярной экономики }\end{array}$ & $\begin{array}{l}\text { Циркулярная эконо- } \\
\text { мика это экономичес- } \\
\text { кая система для смены } \\
\text { парадигмы }\end{array}$ \\
\hline
\end{tabular}

Примечание - Разработано авторами с использованием [4-5].

Исследователи отмечают, что переход к экономике замкнутого цикла, где стоимость продуктов, материалов и ресурсов невысока, позволяет повышать устойчивость экономике, и при этом образование отходов постепенно сводится к минимуму. В этом плане отмечается значительный вклад и усилия стран ЕС по развитию устойчивого, низкоуглеродного, ресурсоэффективного и конкурентоспособной модели экономики. Переход к экономике замкнутого цикла - это возможность для европейских стран трансформировать эконо- мики, создавая новые рабочие места и новые конкурентные преимущества [8].

Также эксперты отмечают, что циркулярная экономика, основанная на процессах переработки, восстановления и повторного использования, может способствовать устойчивому экономическому росту, созданию рабочих мест в экономике и, в конечном итоге, стимулировать предпринимателей вкладывать средства в программы переработки [9]. Это обстоятельство особенно востребовано в условиях, когда ограниченный объем 
ресурсов беспокоит экономистов, а также государственные органы, и они начинают искать пути наилучшего решения для ответа на вызовы все более растущего потребительского экономика и изменение климата [10].

Стоит отметить, что в научной среде накоплен значительный опыт исследований по таким важным вопросам, как принципы организации циркулярной экономики, стратегии, дизайн продуктов и бизнес-модели (Bocken et al., 2016; Lewandowski, 2016; Bakker и другие, 2014). Также необходимо обратить внимание на исследование, раскрывающее различные взаимосвязи между моделями циркулярной экономики и устойчивого развития (Geissdoerfer et al., 2017).

Важный вывод сделан в рамках исследования Lakatos et al., в котором авторы пришли к выводу, что переработка - это ключевой фактор с точки зрения процедур обращения с отходами, что подразумевает биологическую обработку или переработку материалов, а именно анаэробное сбраживание и компостирование, которые вносят значительный вклад во взаимосвязь между циркулярной экономикой и устойчивостью [11].

Но несмотря на это, важно принимать во внимание, что система управления развитие-м циркулярной экономики должна быть реализована для преобразования линейной экономики в экономику замкнутого цикла. Устойчивость переходных моделей были проанализированы в работах авторов [12]. Был сделан вывод, что моделирование отраслевых взаимозависимостей требует, как качественного, так и количественного анализа. По этой причине не существует идеальной интегративной модели управления, которая в совокупности учитывает все экзогенные переменные по причинам, которые, насколько это возможно, что видно, связаны с постоянной эволюцией зависимостей и множеством индикаторов.

Такой вывод наталкивает на идею, что для проведения полноценного экономического анализа, необходимо адаптироваться к экономической ситуации каждой страны, скорректированной в соответствии с политикой государства и спросом со стороны частных компаний в отношении технологий, способствующих сохранению окружающей среды и для продвижения продуктов, полученных из вторсырья, и для биоэнергетики [13].

Особенно интересным представляется исследование, в рамках которого было проанализирована взаимосвязь между переработкой и возобновляемыми источниками энергии, а также экономическим развитием. Эмпирические данные в рамках этого исследования показывают, что возобновляемые источники энергии являются важными политическими факторами для обеспечения устойчивого экономического развития с меньшим негативным эффектом на состояние климата [6].

\section{Методология}

Цель данного исследования заключается в изучении подходов измерения показателей циркулярной экономики, используемых в странах Европейского союза и в странах ОЭСР для формирования понимания применимости представленных методик в условиях экономики Республики Казахстан. Для достижения поставленной в исследовании цели были подобраны данные в виде следующих блоков: экономические показатели, показатели сектора энергетики, выбросов окружающей среды, инноваций и урбанизации. На основании выбранных переменных была построена модель, которая позволяет оценить влияние показателей на вторичное использование ресурсов. В качестве целевого показателя были взят показатель CMU коэффициент циркуляции. Данный показатель измеряет долю материала, извлеченного и возвращенного в экономику. Европейская комиссия выпустила основу для мониторинга прогресса в направлении экономики замкнутого цикла. Этот индикатор является частью этой системы мониторинга и используется для отслеживания прогресса в направлении экономики замкнутого цикла.

Коэффициент цикличного использования материалов (CMU), также известный как коэффициент циркуляции, представляет собой долю используемых материальных ресурсов, полученных из переработанных продуктов и восстановленных материалов, что позволяет экономить извлечение первичного сырья. Скорость замкнутого цикла является частью системы мониторинга замкнутой экономики ЕС [14].

Индикатор включает потоки ресурсов, но не включает потоки воды. Он включает потоки ископаемого топлива и энергоносителей. При этом стоит обратить внимание, что одно только количество материала, возвращаемого в экономику, измеренное в абсолютном выражении, не обязательно представляют круговорот экономики. Количество повторно подаваемого вторичного материала может увеличиваться с той же скоростью, что и общее количество материалов. Именно поэтому для получения 
реальной картины важно использовать систему показателей. Но при этом, стоит отметить, что использование этого коэффициента связано с его универсальностью.

Более высокое значение индикатора CMU означает, что большее количество вторичных материалов заменяет первичное сырье и таким образом снижается воздействие на окружающую среду при добыче первичного материала. Данный индикатор измеряет способность страны производить вторичное сырье и его усилия по сбору отходов для переработки. В открытых экономиках страны представляют собой экономику с потоками импорта и экспорта отходов, собранных в одной стране, но переработанных в других. В этом случае производство (вторичного сырья) и сбор (отходов для вторичной переработки) в одной стране не может быть тождественным. Следовательно, скорость циркуляции измерима на одном или другом потоке. В зависимости от искомого подхода индикатор скорости циркуляции может иметь разные технические характеристики [15].

Показатель циркуляции (CMU) определяется с точки зрения всех материалов, которые используются в нашей экономике, а не только отходов. Это означает, что показатель может быть увеличен многими способами, чем уровень переработки, и требует более глубоких преобразований в наших обществах. Например, замена носителей ископаемого топлива возобновляемыми источниками энергии, использование более эффективных производственных технологий или продление срока службы товаров.

Подобные показатели отражают положение дел как на микро, мезо, так и на макроуровне, связывая уровни посредством определения скорости циркуляции в единый индикатор. В данном исследовании для определения факторов, влияющих на показатель циркуляции, рассматриваются показатели макроуровня. Так в процессе исследования была выдвинута гипотеза о значимом влиянии потребления энергии, затрат на НИОКР и ВВП на данный индикатор.

Для построения финальной модели индикатора циркуляции были использованы данные 28 стран Европейского союза за последние 10 лет и методология Европейского статистического комитета (Eurostat) по циркулярной экономике [15]. Методология Евростата является наиболее полной среди всех известных страновых методологий учета циркулярной экономики. В таблице 2 приведены переменные, которые были использованы для оценки модели и их кодировку для базы расчетов.

Таблица 2 - Описание выбранных переменных для построения модели

Table 2 - Description of the selected variables for building the model

\begin{tabular}{|l|l|}
\hline \multicolumn{1}{|c|}{ Переменная } & \multicolumn{1}{|c|}{ Описание } \\
\hline Circularity rate & $\begin{array}{l}\text { доля материала, извлеченного и } \\
\text { возвращенного в экономику }\end{array}$ \\
\hline EO2 & $\begin{array}{l}\text { Интенсивность выбросов CO2 } \\
\text { (кг на кг нефтяного эквивалента } \\
\text { использования энергии) }\end{array}$ \\
\hline GDPcapita & $\begin{array}{l}\text { Уровень энергоемкости первич- } \\
\text { ной энергии (МДж в ценах 2011 } \\
\text { по ППС ВВП) }\end{array}$ \\
\hline RD & ВВП на дущу населения \\
\hline Urban & $\begin{array}{l}\text { Затраты на исследования и раз- } \\
\text { работки (\% от ВВП) }\end{array}$ \\
\hline
\end{tabular}

Примечание - Составлено авторами.

На основании полученных данных можно сделать вывод, что пропущенных данных нет, панель сбалансирована. Как было отмечено выше, в исследовании были проанализированы данные 28 стран Европейского союза. Данные страны были выбраны случайно, чтобы иметь возможность применить методы анализа панельных данных, которые основаны на стохастической постановке задачи с независимыми, одинаково распределенными выбранными объектами наблюдения.

На рисунке 1 представлены данные по нескольким странам ЕС и по всему союзу в целом. В 2019 году показатель циркуляции в Европейском союзе (ЕС) составлял 12,4\%. Это означает, что $12,4 \%$ материальных ресурсов, используемых в ЕС, приходятся на переработанные продукты и восстановленные материалы, что позволяет избежать извлечения первичного сырья. Этот показатель является частью мониторинга циркулярной экономики ЕС.

В период с 2010 по 2019 год показатель циркулярности в целом по ЕС увеличился с 11,2 до 12,4. Самый высокий показатель в Нидерландах $(28,5 \%)$ и Бельгии $(24 \%)$, самые низкие в Румынии $(1,5 \%)$ и Ирландии $(1,6 \%)$. 


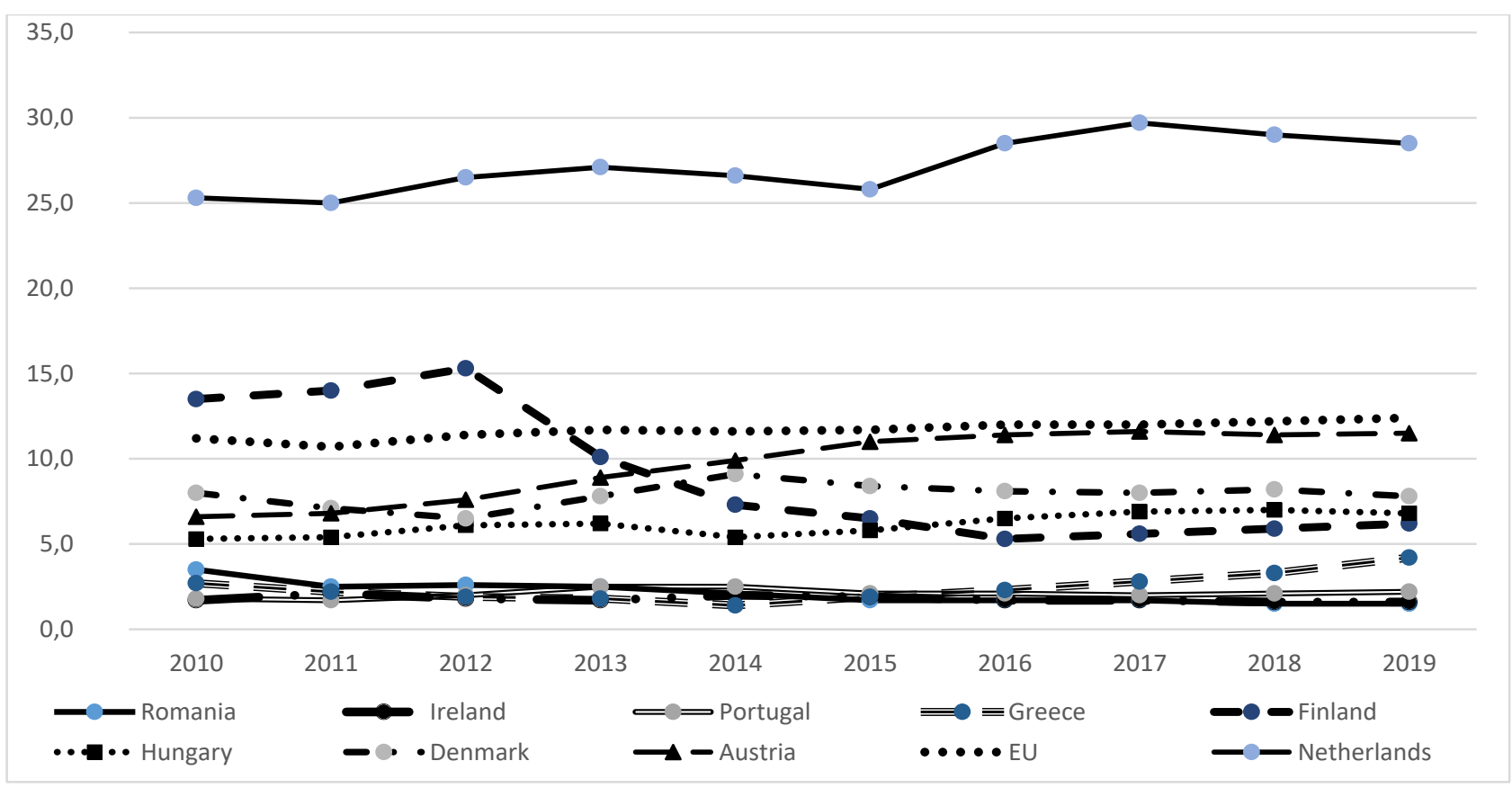

Рисунок 1 - Динамика показателей по странам ЕС за 2010-2019 гг.

Figure 1 - Dynamics of indicators across the EU countries for 2010-2019

Примечание - Составлено авторами с использованием статистических данных Eurostat.

Показатель циркуляции намного ниже, чем другие показатели, характеризующие циркулярную экономику, такие как уровень переработки, который в ЕС составляет около 56\% (это доля переработанных отходов). Это связано с тем, что коэффициент циркуляции имеет гораздо более широкий материальный диапазон: он включает все материалы, которые используются в нашей экономике, тогда как коэффициенты переработки учитывают только отходы.

Для построения модели панельных данных в первую очередь нужно выбрать между моделью с фиксированными либо случайными эффектами. Так, согласно результатам теста Хаусмана, $\chi 2$-статистика равна 6,83 и вероятность (p-value) равна 0,23, что говорит о том, что гипотеза о значимом расхождении оценок по моделям с фиксированными и случайными эффектами не отклоняется (таблица 3). Применяя тест Хаусмана получаем, что для показателя циркуляции предпочтительна модель с случайными эффектами. Модель со случайными эффектами отличается от модели с фиксированными эффектами и общих моделей тем, что не используется метод наименьших квадратов, а используется принцип максимального правдоподобия. Таким образом, в модели согласно теории нас интересует поведение совокупности в целом, т.е. вывод делается относительно характеристик генеральной совокупности и можно обобщать выводы за пределы выборки, использованной в модели [16-18].

Таблица 3 - Результаты теста Хаусмана согласно программе Eviews

Table 3 - Results of the Hausman test according the Eviews program

\begin{tabular}{|c|c|c|}
\hline Статистика & $\begin{array}{c}\text { Число степеней } \\
\text { свободы }\end{array}$ & Вероятность \\
\hline 6.829479 & 5 & 0.2336 \\
\hline
\end{tabular}

Примечание - Составлено авторами на основании программы Eviews.

В качестве зависимой переменной был взят индикатор циркуляции. В качестве независимых переменных, оказывающих влияние на коэффициент циркуляции, в модели статистически значимы оказались три фактора. В результате, получаем модель из трех независимых переменных и свободного члена, представленную в таблице 4. 
Таблица 4 - Модель коэффициента циркулярности согласно программе Eviews

Table 4 - Model of the circularity coefficient according the Eviews program

\begin{tabular}{|c|r|r|}
\hline Переменные & Коэффициент & t-статистика \\
\hline C & -11.18849 & -3.569047 \\
\hline ENINTENSITY & 0.985150 & 3.519367 \\
\hline LNGDP & 0.770625 & 4.007390 \\
\hline LNRD & 0.571359 & 5.248195 \\
\hline
\end{tabular}

Примечание - Составлено авторами на основании программы Eviews.

Мы видим, что все полученные оценки имеют значение $\mathrm{t}$-статистики больше критического по модулю. Из этого следует, что гипотеза о равенстве нулю этих коэффициентов отвергается с вероятностью ошибки, равной 0,05 и полученные коэффициенты значимы. Итак, можно сделать следующий вывод: данные переменные влияют на показатель циркуляции по панели стран ЕС.

Уравнение для моделирования коэффициента циркуляции приобретает следующий вид:

Circularity rate $=\mathrm{f}($ Energy intensity, GDP per energy use, $\mathrm{R} \& \mathrm{D})$

Bce переменные модели были взяты в логарифмической форме. В соответствии с расчетами модели представленные факторы, имеют влияние на показатель циркуляции и представлены в таблице 5.

Таблица 5 - Оценка влияния выделенных факторов на коэффициент циркуляции

Table 5 - Assessment of the influence of the selected factors on the circulation coefficient

\begin{tabular}{|l|l|}
\hline $\begin{array}{c}\text { Рост фактора на единицу } \\
\text { вызывает: }\end{array}$ & $\begin{array}{c}\text { Изменение объема } \\
\text { инвестиций }\end{array}$ \\
\hline $\begin{array}{l}\text { Уровень энергоемкости } \\
\text { (МJ/\$2011 РPP GDP) }\end{array}$ & $+0,99$ \\
\hline ВВП на душу населения & $+0,77$ \\
\hline $\begin{array}{l}\text { Затраты на исследования и } \\
\text { разработки }\end{array}$ & $+0,57$ \\
\hline \multicolumn{2}{|l|}{} \\
\hline Примечание - Составлено авторами. \\
\hline
\end{tabular}

Согласно результатам модели (таблица 5) на долю материалов переработанных и возвращенных обратно в оборот (показатель циркуляции) оказывают влияние энергетические переменные, затраты на НИОКР и уровень ВВП на душу населения (в котором отражается влияние роста населения): $1 \%$ изменение уровня энергоемкости приводит к росту доли переработки материалов на $0,99 \%$, рост ВВП к $0,77 \%$ росту, а увеличение затрат на исследования (рост технологичности экономики) на $0,57 \%$.

Из модели следует, что рост ВВП и рост энергоемкости вместе с повышением уровня технологий в экономике ведет к росту переработки материалов и их повторному использованию в экономическом обороте. Данное влияние отражает с одной стороны влияние роста населения и экономики, которые приводят к необходимости повышения уровня циркуляции материалов вследствие их ограниченности, но с другой стороны показывает существенное влияние новых технологий и затрат на НИОКР на переход к цикличной (циркулярной) экономике.

Для достижения лучших результатов в необходимо инвестировать больше финансовых ресурсов в такие виды деятельности, как НИОКР, разработка новых технологий и инновации. Очень важно также более активное вовлечение потребителей и бизнеса в деятельность, способствующую циркулярной экономике. Достижение этих двух целей будет способствовать обеспечению устойчивого экономического развития

Данные расчетов по панели стран применим к условиям Казахстана, что позволяет использовать ее для анализа существующих тенденций и выработки рекомендаций по совершенствованию развития цикличной экономики.

\section{Результаты и обсуждение}

Как отмечалось выше, предложенная модель позволяет не только получить данные, сопоставимые и рассчитанные по европейской методологии, но также и политику цикличной экономики в Казахстане. В рамках исследования было важно изучить подходы и изменения в измерениях, т.к. после утверждения Пакета циркулярной экономики (ЕС, 2015), ЕС предоставил в 2018 году систему мониторинга, которая направлена на измерение прогресса циркулярной экономики на всех этапах жизненного цикла ресурсов, продуктов и услуг [19].

Новая стратегия действий Европейского союза по циркулярной экономике, утвержденная в 2020 году, является одним из элементов Европейского зеленого курса, нацелен на развитие и изменение системы оценивания и мониторинга (EC, 2020) [20]. Таким образом, он будет сосредоточен на показателях отдельных секторов (например, 
строительстве, производстве пластмасс, текстиля и электроники), производстве экологичной продукции, инновациях и экологичности политики ЕС [21]. Европейская комиссия выделяет десять индикаторов, некоторые из которых являются субиндикаторами и нацелены на потребление и производство (обеспеченность ЕС сырьем, зеленые государственные закупки, образование отходов и т.п.); управление отходами (показатели переработки мусора из различных материалов, утилизация строительного мусора и т.п.); вторичное сырье (показатель циркуляции, показатели утилизации и т.п.); и конкурентоспособность и инновации (частные инвестиции, рабочие места и добавленная стоимость, количество патентов, связанные с секторами экономики замкнутого цикла.).

Стоит отметить, что на сегодня лишь некоторые страны смогли построить эффективные системы мониторинга для циркулярной экономики, которые признаны и действуют на государственном уровне. Среди таких стран в первую очередь стоит отметить Нидерланды и Францию, система которых включает 10 ключевых показателей по основным направлениям, например в Словении такая система включает только три показателя.

В различных европейских странах национальные системы мониторинга в основном основаны на системе мониторинга EC. В Испании стратегия замкнутой экономики, утвержденная в 2020 году, включает ряд показателей, предложенных ЕС. Кроме того, он также содержит два дополнительных показателя по сравнению с рамками ЕС: вклад парниковых газов сектора отходов и степень готовности к повторному использованию отходов. В Нидерландах система мониторинга замкнутой экономики «Циркулярная экономика: что мы хотим знать и можем измерить» также основана на предложениях EC по мониторингу циркулярной экономики [22-23].

Нельзя не отметить, что процесс разработки национальных стратегий еще активно продолжается. В Бельгии правительство запустило Федеральную дорожную карту для стратегии циркулярной экономики [22]. Эта карта позволит реализовать мероприятия, направленные на более ответственное отношение и потребление ресурсов. Также эта дорожная карта включает в себя основную цель - сбор данных, формирование системы оценивания и мониторинга, а также определение задач в рамках поставленной цели. Так, например индикатор переработки и повторного использования отходов - типичный показатель реагирования, который показывает, какая доля всех отходов или отходов конкретной категории подвергается переработке и повторному использованию.

Хотя разработка систем измерения для циркулярной экономики все еще только начинается, можно наблюдать некоторые общие препятствия и проблемы, такие как [22]:

- отсутствие согласованного определения циркулярной экономики. Перед созданием системы показателей важно понять и определить, что следует измерять, причины для этого и целевую аудиторию. Различные определения циркулярной экономики могут привести к различным способам ее измерения.

- отсутствие согласованности показателей. Не существует согласованной системы измерения, способствующей более глубокому пониманию экономики замкнутого цикла и ее оценке с течением времени (Blomsma and Brennan, 2017 [24]) и отсутствует достаточно разработанная и согласованная методология для мониторинга и оценки процессов циркулярной экономики. Так наличие широкого спектра показателей затрудняет оценку надежности и надежности предоставленной информации (OECD, 2020 [25]).

- Неполная информация. В статистической отчетности наблюдаются пробелы в данных и несоответствия, в основном из-за того, что некоторые параметры циркулярной экономики исторически не отражались в статистических базах данных [22].

- Отсутствие интеграции на макромикро-мезоуровнях. Отсутствие интеграции между макро-микро-мезоуровнями влечет за собой риск возникновения противоречивых стратегий [22].

- фокусировка только на показателях переработки отходов. Некоторые индикаторы, используемые для измерения циркулярности (например, часто применяемые - сбор и переработка отходов), могут давать неверные данные о прогрессе, поскольку они не обязательно показывают, как сокращается и оптимизируется первичное потребление материалов (Haupt, Vadenbo and Hellweg, 2017 [26]). Статистических данных об отходах и потоках материалов недостаточно для оценки многих аспектов, связанных с замкнутой экономикой, таких как материальные потери и качественные аспекты рециркуляции.

- Доступные индикаторы в основном ориентированы на данные, а не на цели. Некоторые системы мониторинга характеризуются наличием данных, что в некоторых случаях приводит к чрезмерному представ- 
лению секторов с большей доступностью информации (например, показателей, связанных с отходами, как представлено ниже в таблице 6, по статистическим данным по Казахстану). Существующие индикаторы сосредоточены в основном на физических характеристиках без анализа использования продуктов. Как правило, индикаторы не сосредотачиваются на разумном использовании товаров.

- Отсутствует системный подход к показателям замкнутой экономики. Чтобы перейти к системным изменениям, необходимо, чтобы индикаторы измеряли и контролировали несколько факторов (например, от городского планирования до потребления материалов) и не ограничивались очень конкретными секторами, такими как управление отходами [25].

В Казахстане в настоящий момент применяется только один из рекомендованных ЕС и ОЭСР блоков индикаторов циркулярной экономики (таблица 6). На основании данных таблицы 6 мы видим, что за указанный семилетний период, в основном наблюдается положительная динамика по переработке, вторичного использования по всем видам отходов, кроме опасных видов, где идет не только снижение, но и значительное колебание по некоторым годам.

Таблица 6 - Динамика показателей переработки и повторного использования отходов, используемые в Казахстане по годам

Table 6 - Dynamics of indicators of recycling and reuse of waste used in Kazakhstan by years

\begin{tabular}{|l|c|c|c|c|c|c|c|c|c|}
\hline \multicolumn{1}{|c|}{ Показатели } & $\begin{array}{c}\text { Ед. } \\
\text { изм. }\end{array}$ & 2012 & 2013 & 2014 & 2015 & 2016 & 2017 & 2018 & 2019 \\
\hline $\begin{array}{l}\text { Доля переработки, вторичного } \\
\text { использования ТБО }\end{array}$ & 1,0 & 1,6 & 2,2 & 1,8 & 2,6 & 9,0 & 11,5 & 14,9 \\
\hline $\begin{array}{l}\text { Доля переработки, } \\
\text { вторичного использования } \\
\text { муниципальных отходов }\end{array}$ & $\%$ & 3,8 & 0,5 & 11,1 & 11,5 & 12,3 & 13,0 & 11,6 & 11,1 \\
\hline $\begin{array}{l}\text { Доля переработки, } \\
\text { вторичного использования } \\
\text { промышленных отодов }\end{array}$ & $\%$ & 17 & 18 & 23 & 23,12 & 26,8 & 30,9 & 32,2 & 34,0 \\
\hline $\begin{array}{l}\text { Доля переработки, вторичного } \\
\text { использования опасных } \\
\text { отходов }\end{array}$ & $\%$ & 26,9 & 21,5 & 32,8 & 29,6 & 22,2 & 150,4 & 20,0 & 20,3 \\
$\begin{array}{l}\text { Примечани - Составлено авторами на основании данных Бюро национальной статистики Агентства по } \\
\text { стратегическому планированию и реформам Республики Казахстан [27]. }\end{array}$
\end{tabular}

Как отмечалось выше несмотря на то, что в мире все еще идет совершенствование систем измерений для оценки параметров циркулярной экономики, важно принять определенную систему ее оценивания и определить политику в ее отношении. В Казахстане, к сожалению, данные, собираемые статистическим органом, не могут полностью обеспечить информацией по циркулярной экономики. Для расчета собираются только данные по переработке и сбору отходов. В то время, как в некоторых европейских странах используется десять блоков показателей, например в Нидерландах.

\section{Заключение}

Тема исследования определяет применение концепции циркулярной экономики и то, как внедрение циркулярной экономики повлияло на экономический рост. Наиболее распространенная линейная экономическая модель основана на убеждении, что ресурсы безграничны и что существует безграничное пространство для захоронения отходов. Но данная модель явно неустойчива, и требует кардинальных изменений в подходах еe функционирования.

Концепция циркулярной экономики остается недостаточно понятным термином для всех участников экономической деятельности и широкой общественности. Переход $к$ цикличной или циркулярной экономике требует не только изменения одного вида деятельности, но и системных изменений в промышленности, социальных компонентах, энергетике, транспорте, сельском хозяйстве и многом другом. Каждый сектор экономики имеет свои собственные принципы и ограничения, и каждая страна имеет свои особенности, что приводит к различным подходам и временным рамкам для перехода к экономике замкнутого цикла. 
По результатам этого исследования можно сделать вывод, что существует связь между показателями экономического развития, инноваций и циркулярной экономики. Есть различные примеры принятия концепции циркулярной экономики и ее внедрения по всему миру с отличными результатами, из которых можно разработать концепцию переходя для Казахстана. Циркулярная модель может генерировать доход и создавать новые рабочие места, в которых нуждается большинство стран.

Реализация концепции циркулярной экономики должна быть не только вопросом государственного вмешательства и субсидий. Компании и граждане могут предпринимать собственные инициативы для перехода, начиная с сортировки и переработки отходов, экономии энергии и т. д. Принятие концепции циркулярной экономики может помочь компаниям опередить потенциальные ограничения, такие как нехватка ресурсов, налогообложение, внешние эффекты и т. д.

Модель экономики замкнутого цикла хорошо сочетает экономические и экологические выгоды, что в дальнейшем способствует развитию предпринимательства. Используя отходы в качестве ресурса и применяя принципы циркулярной экономики, можно достичь новых рубежей в экономическом развитии. Необходимо постоянно стимулировать граждан как в финансовом плане, так и в плане образования, поскольку переход к экономике замкнутого цикла нельзя сводить к вопросу инфраструктуры и технического прогресса. Это требует более активного социального участия, сотрудничества как на местном, так и на национальном уровне, принятия новых бизнес-моделей (побуждающих потребителей переходить на аренду вместо владения), поддержки отраслевых кластеров в торговле побочными продуктами и новой системы городского управления, которая потребует времени, чтобы полностью освоить завершить переход.

Авторы осведомлены об ограничениях этой статьи, одним из которых является тот факт, что некоторые переменные имеют очень низкое прогностическое значение вследствие небольшого значения коэффициента детерминации, но связь между переменными являются очевидными и статистически надежными.
Список использованных источников

1. Влияние COVID-19 на ключевые секторы экономики Казахстана. Мнение участников рынка// kpmg.kz [Электронный ресурс]. URL: https://assets. $\mathrm{kpmg} / \mathrm{content} / \mathrm{dam} / \mathrm{kpmg} / \mathrm{kz} / \mathrm{pdf} / 2020 / 05 /$ covid-rkeconomy-sectors.pdf (дата обращения: 23.05.2021).

2. Jawahir, I.S., Bradley, R. (2016). Technological Elements of Circular Economy and the Principles of 6R-Based Closed-loop Material Flow in Sustainable Manufacturing. Procedia CIRP, 40, 103-108. https:// doi.org/10.1016/j.procir.2016.01.067

3. Grdic, S.Z., Nizic, M.K., Rudan, E. (2020). Circular Economy Concept in the Context of Sustainability. Sustainability, 12(7), 3060-3071. https:// doi.org/10.3390/su12073060

4. Pearce, D.W, Turner, R.K. (1990). Economics of natural resources and the environment. The John Hopkis University Press, Baltimore.

5. Persson, O. (2015). What is circular economy? - The discourse of circular economy in the Swedish public sector. Uppsala University.

6. Cerqueira, P., Soukiazis, E., Proença, S. (2020). Assessing the linkages between recycling, renewable energy and sustainable development: evidence from the OECD countries. Environment, Development and Sustainability, May, 461-470. https://doi.org/10.1007/ s10668-020-00780-4

7. Сысоева, Е.А. (2019). Циркулярная экономика в контексте устойчивого развития. Проблемы современной экономики, 2(70), 199-204. http://www.m-economy.ru/art.php?nArtId=6642

8. Material, flows in the circular economy. [Электронный ресурc]. URL: https://ec.europa.eu/ eurostat/statistics-explained/index.php?title=Material_ flows_in the circular_economy\#Sankey_diagram_of material_flows (дата обращения: 23.05.2021).

9. Chang, N.B. (2008). Economic and policy instrument analyses in support of the scrap tire recycling program in Taiwan. Journal of Environment Management, 86, 435-450. https://doi.org/10.1016/j. jenvman.2006.12.026

10. Trica, C.L., Banacu, C.S., Busu, M. (2019). Environmental Factors and Sustainability of the Circular Economy Model at the European Union. Sustainability, 11, 1114-1123. https://doi.org/10.3390/su11041114

11. Lakatos, E.S., Cioca, L.I., Dan V., Ciomos A.O., Crisan O.A., Barsan G. (2018). Studies and Investigation about the Attitude towards Sustainable Production, Consumption and Waste Generation in Line with Circular Economy in Romania. Sustainability, 10, 865-897. https://doi.org/10.3390/su10030865

12. Hockings, M., Stolton, S., Leverington, F., Dudley, N. (2006). Evaluating Efectiveness: A Framework for Assessing Management Eectiveness of Protected Areas. IUCN. 2006.

13. Angenendt, G., Zurmühlen, S., Axelsen, H., Sauer, D.U. (2018). Comparison of different operation strategies for PV battery home storage systems including forecast-based operation strategies. Applied Energy, 229, 884-899. $\quad$ https://doi.org/10.1016/j. apenergy.2018.08.058

14. Material flows in the circular economy. URL: https://ec.europa.eu/eurostat/statistics-explained/index. 
php?title=Material flows in the circular economy (дата обращения: 01.04.2021).

15. Circular material use rate calculation method. Luxembourg: Publications Office of the European Union, 2018. [Электронный ресурc]. URL: https:// ec.europa.eu/eurostat/web/products-manualsand-guidelines/-/ks-gq-18-013 (дата обращения: 23.05.2021).

16. Brooks, C. (2008). Introductory Econometrics for Finance. Cambridge.

17. Baltagi B. (2005). H. Econometric Analysis of Panel Data. Wiley.

18. Arellano, M. (2003). Panel Data Econometrics. Advanced Texts in Econometrics. Oxford University Press.

19. EC (2015). EU Action Plan for the Circular Economy.European Commission [Электронный pecypc]. URL: https://ec.europa.eu/environment/ circular-economy/index en.htm. (дата обращения 15.05.2021)

20. EC (2020). New Circular Economy Strategy. European Commission [Электронный ресурc]. URL: https://ec.europa.eu/environment/circular-economy/ (дата обращения 22.03.2021)

21. OECD (2020). OECD - Nordic Innovation webinars on the circular economy in cities and regions [Электронный ресурc]. URL: http://www.oecd. org/cfe/regionaldevelopment/highlights-2nd-OECDroundtable-circular-economy.pdf (дата обращения: 23.05.2021).

22. OECD (2020) The Circular Economy in Cities and Regions [Электронный pecypc]. URL: https://www.oecd-ilibrary.org/sites/16f47a98-en/index. html?itemId=/content/component/16f47a98-en (дата обращения 23.05.2021).

23. Netherlands Environmental Assessment Agency (2018). Circular economy: What we want to know and can measure [Электронный ресурс]. URL: https://circulareconomy.europa.eu/platform/ sites/default/files/pbl-2018-circular-economy-whatwe-want-to-know-and-can-measure-3216.pdf (дата обращения 23.05.2021).

24. Blomsma, F., Brennan, G. (2017). The emergence of circular economy: A new framing around prolonging resource productivity. Journal of Industrial Ecology, 21 (3), 603-614. http://dx.doi.org/10.1111/ jiec. 12603

25. OECD (2020). OECD - Nordic Innovation webinars on the circular economy in cities and regions [Электронный pecypc]. URL: http://www.oecd. org/cfe/regionaldevelopment/highlights-2nd-OECDroundtable-circular-economy.pdf (дата обращения: 24.05.2021)

26. Haupt, M., Vadenbo, C., Hellweg, S. (2017). Do we have the right performance indicators for the circular economy? Insight into the Swiss waste management system. Journal of Industrial Ecology, 21(3), 615-627. http://dx.doi.org/10.1111/jiec.12506

27. Охрана окружающей среды в Республике Казахстан. Статистический сборник (2020). НурСултан. Электронный ресурс]. URL: https://stat.gov. kz/edition/publication/collection (дата обращения: 23.05.2021).

\section{References}

1. Impact of COVID-19 on key sectors of the economy of Kazakhstan. The opinion of market participants // kpmg.kz [Electronic resource]. URL: https://assets.kpmg/content/dam/kpmg/kz/pdf/2020/05/ covid-rk-economy-sectors.pdf (date of access 23.05.2021).

2. Jawahir, I.S., Bradley, R. (2016). Technological Elements of Circular Economy and the Principles of 6R-Based Closed-loop Material Flow in Sustainable Manufacturing. Procedia CIRP, 40, $103-108$. https:// doi.org/10.1016/i.procir.2016.01.067

3. Grdic, S.Z., Nizic, M.K., Rudan, E. (2020). Circular Economy Concept in the Context of Sustainability. Sustainability, 12(7), 3060-3071. https:// doi.org/10.3390/su12073060

4. Pearce, D.W., Turner, R.K. (1990). Economics of natural resources and the environment. The John Hopkis University Press, Baltimore.

5. Persson, O. (2015). What is circular economy? - The discourse of circular economy in the Swedish public sector. Uppsala University.

6. Cerqueira, P,. Soukiazis, E., Proença, S. (2020). Assessing the linkages between recycling, renewable energy and sustainable development: evidence from the OECD countries. Environment, Development and Sustainability, May, 461-470. https://doi.org/10.1007/ s10668-020-00780-4

7. Sysoeva, E.A. (2019). Cirkuljarnaja jekonomika v kontekste ustojchivogo razvitija. Problemy sovremennoj jekonomiki, 2 (70), 199-204. http:// www.m-economy.ru/art.php?nArtId=6642

8. Material flows in the circular economy. [Electronic resource]. URL: https://ec.europa.eu/eurostat/ statistics-explained/index.php?title=Material_flows in the circular_economy\#Sankey_diagram_of_material flows (date of access 23.05.2021).

9. Chang, N.B. (2008). Economic and policy instrument analyses in support of the scrap tire recycling program in Taiwan. Journal of Environment Management, 86, 435-450. https://doi.org/10.1016/j. jenvman.2006.12.026

10. Trica, C.L., Banacu, C.S., Busu, M. (2019). Environmental Factors and Sustainability of the Circular Economy Model at the European Union. Sustainability, 11, 1114-1123. https://doi.org/10.3390/su11041114

11. Lakatos, E.S., Cioca, L.I., Dan,V., Ciomos A.O., Crisan O.A., Barsan G. (2018). Studies and Investigation about the Attitude towards Sustainable Production, Consumption and Waste Generation in Line with Circular Economy in Romania. Sustainability, 10, 865-897. https://doi.org/10.3390/su10030865

12. Hockings, M., Stolton, S., Leverington F., Dudley N. (2006). Evaluating Efectiveness: A Framework for Assessing Management Eectiveness of Protected Areas. IUCN. 2006.

13. Angenendt, G., Zurmühlen, S., Axelsen, H., Sauer D.U. (2018). Comparison of different operation strategies for PV battery home storage systems including forecast-based operation strategies. Applied Energy, 229, 884-899. $\quad$ https://doi.org/10.1016/j. apenergy.2018.08.058 
14. Material flows in the circular economy. [Electronic resource]. URL: https://ec.europa.eu/ eurostat/statistics-explained/index.php?title=Material flows in the circular economy (date of access 01.04.2021).

15. Circular material use rate calculation method. Luxembourg: Publications Office of the European Union, 2018. [Electronic resource]. URL: https://ec.europa.eu/eurostat/web/productsmanuals-and-guidelines/-/ks-gq-18-013(date of access 23.05.2021).

16. Brooks, C. (2008). Introductory Econometrics for Finance. Cambridge.

17. Baltagi B. (2005). H. Econometric Analysis of Panel Data. Wiley.

18. Arellano, M. (2003). Panel Data Econometrics. Advanced Texts in Econometrics. Oxford University Press.

19. EC (2015). EU Action Plan for the Circular Economy.European Commission [Electronic resource]. URL: $\quad$ https:/ec.europa.eu/environment/circulareconomy/index en.htm. (date of access 15.05.2021)

20.EC (2020). New Circular Economy Strategy. European Commission [Electronic resource]. URL: https://ec.europa.eu/environment/circular-economy/ (date of access 22.03.2021)

21. ECD (2020). OECD - Nordic Innovation webinars on the circular economy in cities and regions [Electronic resource]. URL: http://www.oecd.org/ cfe/regionaldevelopment/highlights-2nd-OECDroundtable-circular-economy.pdf (date of access 23.05.2021) .
22. OECD (2020) The Circular Economy in Cities and Regions [Electronic resource]. URL: https:// www.oecd-ilibrary.org/sites/16f47a98-en/index. html?itemId=/content/component/16f47a98-en (date of access 23.05.2021).

23. Netherlands Environmental Assessment Agency (2018). Circular economy: What we want to know and can measure [Electronic resource]. URL: https://circulareconomy.europa.eu/platform/sites/ default/files/pbl-2018-circular-economy-what-wewant-to-know-and-can-measure-3216.pdf (date of access 23.05.2021).

24. Blomsma, F., Brennan, G. (2017). The emergence of circular economy: A new framing around prolonging resource productivity. Journal of Industrial Ecology, 21 (3), 603-614. http://dx.doi.org/10.1111/ jiec. 12603

25. OECD (2020). OECD - Nordic Innovation webinars on the circular economy in cities and regions [Electronic resource]. URL: http://www.oecd.org/ cfe/regionaldevelopment/highlights-2nd-OECDroundtable-circular-economy.pdf (date of access 24.05.2021)

26. Haupt, M., Vadenbo, C., Hellweg, S. (2017). Do we have the right performance indicators for the circular economy? Insight into the Swiss waste management system. Journal of Industrial Ecology, 21(3), 615-627. http://dx.doi.org/10.1111/jiec.12506

27. Ohrana okruzhajushhej sredy v Respublike Kazahstan. Statisticheskij sbornik (2020). Nur-Sultan. URL: https://stat.gov.kz/edition/publication/collection (date of access 23.05.2021).

\section{Information about the authors}

* Arsen M. Tleppayev - PhD (Economics), Associate Professor, Faculty of Economics and Business, KazakhGerman University, 111 Pushkin Str., 050010, Almaty, Kazakhstan, e-mail: arsentlp@gmail.com. ORCID ID: https:// orcid.org/0000-0001-9754-3383

Saule Zh. Zeinolla - PhD (Economics), Associate Professor, Academy of Public Administration under the President of the Republic of Kazakhstan, 134 Dostyk Str., 050051, Almaty, Kazakhstan, e-mail: zeinollasaule@gmail.com. ORCID ID: https://orcid.org/0000-0002-9504-9629

\section{Авторлар туралы мәліметтер}

* Тлеппаев Арсен - PhD, доцент, экономика және кәсіпкерлік факультеті, Қазақстан-Неміс Университеті, Пушкина 111, 050010, Алматы, Казахстан, e-mail: arsentlp@gmail.com. ORCID ID: https://orcid.org/0000-0001$\underline{9754-3383}$

Зейнолла Сауле - PhD, доцент, Қазақстан Республикасы Президентінің жанындағы Мемлекеттік басқару академиясы, Достык 134, 050051, Алматы, Казахстан, e-mail: zeinollasaule@gmail.com. ORCID ID: https://orcid. org/0000-0002- 9504-9629

\section{Сведения об авторах}

* Тлеппаев Арсен - PhD, доцент, факультет экономики и предпринимательства, Казахстанско-Немецкий Университет, Пушкина 111, 050010, Алматы, Казахстан, e-mail: arsentlp@gmail.com. ORCID ID: https://orcid. org/0000-0001-9754-3383

Зейнолла Сауле - $\mathrm{PhD}$, доцент, Академия государственного управления при Президенте Республики Казахстан, Достык 134, 050051, Алматы, Казахстан, e-mail: zeinollasaule@gmail.com. ORCID ID: https://orcid. org/0000-0002- 9504-9629 